\title{
CDISC SEND Study Design Terminology
}

National Cancer Institute

\section{Source}

National Cancer Institute. CDISC SEND Study Design Terminology. NCI Thesaurus. Code C89967.

The terminology that includes concepts relevant to the Clinical Data Interchange Standards Consortium (CDISC) Standard for the Exchange of Non-clinical Data (SEND) study design. 